IZA DP No. 8807

Automatic Enrollment, Employer Match Rates and Employee Compensation in 401(k) Plans

Barbara A. Butrica

Nadia S. Karamcheva

January 2015 


\title{
Automatic Enrollment, Employer Match Rates and Employee Compensation in 401(k) Plans
}

\author{
Barbara A. Butrica \\ Urban Institute \\ Nadia S. Karamcheva \\ Urban Institute \\ and IZA \\ Discussion Paper No. 8807 \\ January 2015 \\ IZA \\ P.O. Box 7240 \\ 53072 Bonn \\ Germany \\ Phone: +49-228-3894-0 \\ Fax: +49-228-3894-180 \\ E-mail: iza@iza.org
}

\begin{abstract}
Any opinions expressed here are those of the author(s) and not those of IZA. Research published in this series may include views on policy, but the institute itself takes no institutional policy positions. The IZA research network is committed to the IZA Guiding Principles of Research Integrity.

The Institute for the Study of Labor (IZA) in Bonn is a local and virtual international research center and a place of communication between science, politics and business. IZA is an independent nonprofit organization supported by Deutsche Post Foundation. The center is associated with the University of Bonn and offers a stimulating research environment through its international network, workshops and conferences, data service, project support, research visits and doctoral program. IZA engages in (i) original and internationally competitive research in all fields of labor economics, (ii) development of policy concepts, and (iii) dissemination of research results and concepts to the interested public.
\end{abstract}

IZA Discussion Papers often represent preliminary work and are circulated to encourage discussion. Citation of such a paper should account for its provisional character. A revised version may be available directly from the author. 


\section{ABSTRACT}

\section{Automatic Enrollment, Employer Match Rates and Employee Compensation in 401(k) Plans*}

This study uses restricted-access employer-level microdata from the National Compensation Survey to examine the relationship between automatic enrollment and employee compensation. By boosting plan participation, automatic enrollment has the potential to increase employer defined contribution plan costs as previously unenrolled workers receive matching contributions. Using cross-sectional variation in employer compensation costs and the automatic enrollment provision within firms sponsoring DC plans, we examine differences in compensation between those with and without the provision. A significant negative correlation exists between the generosity of the employer match structure and the automatic enrollment provision. However, we find no evidence that total compensation costs or DC costs differ between firms with and without automatic enrollment, and no evidence that DC costs crowd out other forms of compensation.

JEL Classification: J26, J31, J32

Keywords: automatic enrollment, defined contribution plan costs, employer match generosity, employee wage and non-wage compensation, firm behavior

Corresponding author:

Nadia Karamcheva

Urban Institute

2100 M St. NW

Washington, DC 20037

USA

E-mail: karamche@bc.edu

\footnotetext{
* The research reported herein was pursuant to a grant from the U.S. Social Security Administration (SSA), funded as part of the Retirement Research Consortium (RRC). It was conducted with restricted access to Bureau of Labor Statistics (BLS) data. The findings and conclusions expressed are solely those of the authors and do not represent the views of SSA, BLS, any agency of the federal government, the RRC, the Urban Institute, its board, or its funders. The authors would like to thank Keenan Dworak-Fisher for valuable comments and for his instrumental help in gaining access to and using the data source; as well as Richard Johnson and participants at research seminars at the Urban Institute, the Bureau of Labor Statistics, the Netspar International Pension Workshop, and the 2015 Annual AEA Meeting, for helpful suggestions. All mistakes are our own.
} 


\section{Introduction}

The dramatic rise of employer-sponsored defined contribution (DC) plans in the United States has been accompanied by an increasing concern about the retirement security that DC plans will provide. While the majority of workers participate if offered a plan, a considerable portion, particularly low-earners, fail to sign up. ${ }^{1}$ Moreover, contribution rates among participants are relatively low and many workers do not contribute enough to take full advantage of their employer's match. ${ }^{2}$

To tackle inertia in participation, employers are increasingly automatically enrolling new employees while allowing them to opt out. Some research suggests that the popularity of the provision increased after the passage of the Pension Protection Act (PPA) of 2006, which removed many of the legal barriers to automatically enrolling eligible employees into DC plans (Engelhardt (2011)). A number of studies have documented significant increases in retirement plan participation rates within firms that instituted automatic enrollment (Beshears et al. (2010); Choi et al. (2002), (2004); Madrian and Shea (2001)). Yet, we do not have a good sense of how the increase in participation rates is accommodated by the labor market.

According to standard economic theory, profit maximizing employers operate at the point where the marginal product of labor equals the marginal cost. Since a common way for firms to encourage workers to participate and contribute to retirement plans is to match some percentage or dollar amount of their contributions (Choi et al. (2002)), automatic enrollment likely increases employer costs as previously unenrolled workers begin receiving matching retirement plan contributions when they are automatically enrolled, all else equal.

To restore equilibrium and offset the extra costs associated with automatic enrollment, employers could adjust the other components of their 401(k) plans or any of the other components in their compensation packages. However, if automatic enrollment increases productivity, either directly by affecting the production function and resulting in a positive marginal revenue or cost savings or indirectly by increasing the marginal product of labor, then some of the gains might be passed to employees in the form of higher employee compensation. Thus, productivity gains resulting from the automatic enrollment provision could also result in an equilibrium where opt-out 401(k) packages are associated with higher total compensation costs compared with those with an opt-in 401(k) mechanism. Moreover, the change in total compensation need not affect all components of compensation the same way. Changes in total compensation might translate into changes in wages, health or other benefits, or specific components of the defined contribution pension plans, such as the generosity of the plan match structure.

In this paper we offer cross-sectional evidence on the ways in which compensation packages for workers with 401(k) plans differ for those with and without automatic enrollment. To the best of our knowledge, this is the first paper to address this question. In addition, we use a nationally representative dataset of employers, which provides us with information not only on the specific characteristics of the defined contribution plans offered, such as match generosity and the automatic enrollment provision, but also includes information on the full set of items comprising the total compensation package. We use restricted-access microdata from the National Compensation Survey (NCS), which does not suffer from the measurement and misreporting errors on employee benefits that are commonly observed in household surveys (Gustman and Steinmeier (2004)).

Our results confirm previous findings that plans with automatic enrollment have, on average, higher participation rates. However, we find no evidence that total compensation costs differ significantly between firms with and without automatic enrollment. In addition, we find no evidence that employers with opt-out 401(k)s have defined contribution costs that are any different from employers with opt-in 401(k)s, or any evidence of a crowding-out effect between defined contribution costs and other forms of compensation as a result of automatic enrollment. Finally, we do find that plans with automatic enrollment offer match rates 
that are on average 0.38 percentage points or 11 percent lower than those without automatic enrollment, even when we control for other characteristics. Given the average wage, participation, and match rates of the plans in our sample, this translates into a savings of roughly 7 cents per labor hour, which almost completely offsets the additional costs of 6.5 cents resulting from higher participations rates in automatic enrollment plans.

The paper is organized as follows. In Section 2 we provide background information on DC plans and automatic enrollment. Section 3 describes the data. Section 4 presents descriptive statistics. Section 5 explains our empirical strategy and discusses the results. Sections 6 and 7 provide discussion and conclusion.

\section{Background}

The pension landscape in the United States has been gradually shifting as employers move away from offering their employees defined benefit (DB) pension plans towards offering them DC plans. The rise in DC plans has introduced issues not typically present in DB pensions, such as voluntary participation. In DB pensions, employees are usually automatically enrolled and typically cannot opt out. Although slowly changing, in most DC plans employees must elect to participate. As a result, participation rates among private wage and salary workers in 2012 who were offered an employer retirement plan were 89 percent in DB pensions but only 70 percent in DC plans (U.S. Bureau of Labor Statistics 2012b). ${ }^{3}$

Those employees who are offered plans yet choose not to participate are most concerning to policymakers. Not only are these workers not taking advantage of tax-deferred opportunities to save for retirement, but many are giving money away by not taking advantage of their employer's matching contributions. Recognizing the capacity for automatic enrollment to increase participation in DC plans and thereby increase retirement savings, the U.S. Treasury Department authorized employers' adoption of autoenrollment in 1998 for new hires and again in 2000 for previously hired employees not already participating in their employer's plan (Choi et al. (2004)).

Employers are also concerned about employees who do not enroll in $401(\mathrm{k}) \mathrm{s}$, in part because these employees jeopardize the company's performance on nondiscrimination tests - rules forbidding employers from providing benefits exclusively to highly paid employees. By increasing participation among non-highly compensated employees (NHCEs), automatic enrollment makes it possible for employers to raise or eliminate contribution limits on highly compensated employees (HCEs) - effectively increasing their pension benefits. ${ }^{4}$ In fact, one-fifth of plan sponsors said that improving nondiscrimination test results was their primary motivation for offering automatic enrollment (Sandler, Cole and Green, (2011)). ${ }^{5}$

Automatic enrollment (also known as "negative election" or an opt-out mechanism) is a 401(k) plan feature in which elective employee deferrals begin without requiring the employee to submit a request to join the plan. When automatic enrollment is present, employees who do not select a contribution amount have a predetermined percentage of their pay deferred as soon as they become eligible for the plan. If employees do not want to participate, they must actively request to be excluded from the plan.

Several studies and anecdotal accounts suggest that automatic enrollment has succeeded in dramatically increasing 401(k) participation (Beshears et al., (2010); Choi et al. (2002), (2004); Madrian and Shea (2001)). Madrian and Shea (2001), for example, document a 48 percentage point increase in 401(k) participation among newly hired employees and an 11 percentage point increase in participation overall at one large U.S. company 15 months after the adoption of automatic enrollment. The authors also note that automatic enrollment has been particularly successful at increasing 401(k) participation among employees least likely to participate in retirement savings plans, namely those who are young, lower-paid, black, or Hispanic. 
Various sources point to the increasing popularity of automatic enrollment plans since the passage of the PPA. ${ }^{6}$ A number of cost, fiduciary, and tax incentives in the PPA have been identified as likely drivers behind employers' increased willingness to adopt various automatic provisions, including automatic enrollment, in their 401(k) plans. ${ }^{7}$

\subsection{The Costs of Automatic Enrollment}

Some studies have observed that instituting automatic enrollment might indeed be associated with higher costs. A 2001 Vanguard report outlining the benefits and costs of adopting automatic enrollment noted that the largest expense related to autoenrollment is the money needed to fund any employer match for new enrollees (Andersen et al. (2001)). The same report noted that aside from the extra costs of an employer match, firms adopting automatic enrollment are likely to incur additional costs associated with maintaining and servicing a large number of small accounts - especially if autoenrollment is extended to all eligible employees (Andersen et al. (2001)). A recent survey found among plans that reported being unlikely to adopt autoenrollment, 73 percent cited the increased cost of the employer match as a primary barrier (Hess and Xu (2011)). Sure enough, the majority of plans that automatically enroll employees do this only for new hires. According to the PSCA survey, 82 percent of plans reported that autoenrollment was used only for new hires (PSCA (2011)). There is some evidence that employers are reluctant to backsweep existing nonparticipants because of the desire to minimize employer match contributions and other plan-related costs (Andersen et al. (2001)). At the very least, this evidence suggests that because firms are profit maximizers most will not passively accept the higher employee compensation costs that may be associated with automatically enrolling workers.

We can think of the effects of automatic enrollment, from the point of view of the employer, in a more conceptual way by first decomposing labor compensation costs into their components. Total per labor hour compensation costs (C) can be written as the sum of defined contribution costs (DC) and non-defined contribution costs (NDC) where all costs are a function of automatic enrollment, denoted by $\alpha$. One could think of $\alpha$ as a binary indicator of the presence of automatic enrollment, or as a continuous measure between 0 and 1 that varies with the share of employees the firm automatically enrolls, based on job characteristics such as tenure, income, etc.

$$
C(\alpha)=D C(\alpha)+N D C(\alpha)
$$

Then the effect of changes in $\alpha$ on total compensation can be expressed as:

$$
\frac{\partial C}{\partial \alpha}=\frac{\partial D C}{\partial \alpha}+\frac{\partial N D C}{\partial \alpha}
$$

In addition, defined contribution costs are a function of participation rates, match generosity, employee contribution rates, and wages. That is:

$$
D C(\alpha)=\operatorname{partic}(\alpha) * m(\alpha) * \operatorname{contrib}(\alpha) * w(\alpha)
$$

Taking the first derivative of (3) with respect to $\alpha$ and substituting the result into (2) gives us:

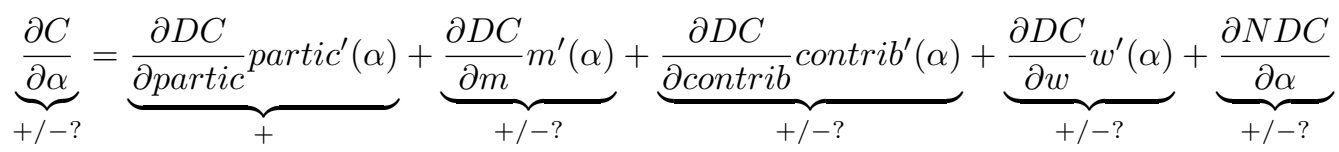

Our empirical specifications focus on estimating the components of equation (4). Since previous literature 
has documented that participation rates increase, at least in the short term, following the implementation of automatic enrollment, we can sign the first term on the right hand side of equation (4). Holding all other factors constant (i.e. assuming the last four terms on the right hand side of equation (4) are zero) suggests that the adoption of automatic enrollment increases employer DC plan costs and therefore total costs due to the increase in participation $\left(\frac{\partial D C}{\partial p a r t i c} \operatorname{partic}^{\prime}(\alpha)>0 \Longrightarrow \frac{\partial D C}{\partial \alpha}>0\right)$ and $\frac{\partial C}{\partial \alpha}>0$.

Previous literature has already discussed some of the levers that employers can use in dealing with the costs of automatic enrollment. As Soto and Butrica (2009) note, employers can: 1) reduce the generosity of the match offered to participating workers, which is the second term on the right-hand-side of equation (4); 2 ) reduce compensation other than pension benefits to keep total compensation at the same level as before the introduction of the autoenrollment feature, which are the fourth and fifth terms on the right-hand-side of equation (4); or 3) leave the pension and other compensation arrangements unchanged, or even increase compensation if automatic enrollment raises productivity.

In their empirical analysis Soto and Butrica (2009) focus on examining the relationship between automatic enrollment and employer contributions or match rates. While the authors's results suggest that automatic enrollment might be associated with lower employer match rates, the only other study that has examined a similar relationship - VanDerhei (2010)- finds contradicting results. VanDerhei (2010) reports higher effective employer match rates in 2009 than in 2005 among plans that adopted automatic enrollment. Both studies, however, have their shortcomings. Soto and Butrica (2009) relied on cross-sectional data which did not allow them to examine changes in the employer match rates following the adoption of automatic enrollment. Data limitations also prevented the authors from being able to separately identify the effect of autoenrollment on employees elective deferrals and the effect on the plans' match structure, so at best they managed to capture only the combined effect of the second and third terms on the right-hand-side of equation (4). While VanDerhei (2010) ) was able to observe match generosity in the same plans in 2005 and 2009, the author's estimates are based on a sample of large 401(k) plans, which are not necessarily nationally representative. Moreover, neither of these studies had the ability to examine the relationship between automatic enrollment and total DC plan costs, and no previous study has examined the correlation between automatic enrollment and non-DC costs or total compensation costs. While our study also relies on cross-sectional data, the NSC is nationally representative and allows us to contribute to the literature by examining all components of total compensation (including the employer match generosity) and their relation to automatic enrollment.

Another way to keep costs down, and one not identified in Soto and Butrica (2009), is for employers to set a low default deferral rate through the third term on the right-hand-side of equation (4). When instituting automatic enrollment, employers must choose a default contribution rate for employees who do not actively select a contribution rate or level. ${ }^{8}$ Although workers can change their contribution rate, studies have shown that automatically enrolled employees tend to remain with the default options of their plan. Madrian and Shea (2001) showed that, at least in the short run, only a small fraction of automatically enrolled 401(k) participants elect a contribution rate or asset allocation that differs from the company-specified default. Additionally, a Vanguard study found that automatic enrollment leads to lower plan contribution rates, as participants who would have voluntarily saved at a higher rate remain at the lower default contribution rates (Nessmith, Utkus, and Young (2007)). The same study also found that the default contribution rate under automatic enrollment does not appear to affect employees decisions to quit the plan. Thus, a potential way for firms to offset the higher match-related costs created by higher participation rates under automatic enrollment is to set low default contribution rates. In the empirical section of the paper we compare the default contribution rates in plans with automatic enrollment with the contribution rates at which workers would maximize their employer match. 


\section{Data}

We use restricted microdata from the National Compensation Survey conducted by the U.S. Bureau of Labor Statistics (BLS). The NCS is a large nationally representative survey that collects information from establishments on occupational earnings, the incidence and costs of employer-sponsored benefits among workers, and the provisions of employer-sponsored benefit plans. The sample covers civilian workers in private industry and state and local governments. ${ }^{9}$

The NCS collects employer-level data on establishment size, region, and industry. It also collects job-level information on unionization, percentage of full-time workers, occupation, participation in retirement plans, the incidence of benefits and provisions of benefit plans, such as insurance (life, short-term disability, and long-term disability), paid leave (sick, vacation, jury, personal, and family) and paid holidays, and detailed plan provisions (i.e. through plan brochures) for health care (medical, dental, vision, and prescription drugs) and retirement plans (defined benefit and defined contribution). It collects pension plan-level data on plan type, match structure, match rates, and automatic enrollment.

The NCS also has information on employer costs. The costs include wages and salaries and a variety of employee benefit categories, such as paid leave, health insurance, and retirement. Each benefit cost is averaged across workers in a particular job, even though there may be some variation among workers within the job in take-up of or eligibility for the benefit (U.S. Bureau of Labor Statistics (2012a)). ${ }^{10}$

For our analysis, we use NCS data from 2010/2011. Since the goal of our analysis is to examine the correlation between automatic enrollment and the components of DC costs and other compensation costs, our sample restrictions are driven by the availability of detailed information on plan characteristics. Our sample includes savings and thrift plans, as these are the only types of plans for which BLS collects information on both the automatic enrollment provision and the match structure. We exclude zero-match plans from our sample because the BLS does not consider these plans to provide employee benefits and therefore does not collect data about their plan features. ${ }^{11}$ To the extent that zero-match plans are more likely to implement automatic enrollment because they face close to no change in cost, excluding them from our sample will potentially bias upward the negative coefficient on automatic enrollment in the regression of match generosity. If that is the case, then the estimated negative correlation between automatic enrollment and employer match rates in our empirical section can be viewed as a conservative upper bound. We also exclude plans for which the employer contributes without requiring minimum employee contributions (typically money-purchase or profit-sharing plans) because the BLS does not collect automatic enrollment information for these plans. We further restrict our sample to include only those plans with flat match rate structures - where a percentage is applied to employees' contributions up to a specified percentage of the employees' salaries - since the BLS collects detailed information on the match structure of only these plans.

Overall, 51 percent of workers in the full NCS sample have a DC plan. Among these workers, 76 percent have a savings and thrift plan, and 69 percent of workers with savings and thrift plans have a flat match structure. After dropping some duplicate records, our final sample includes roughly 3,800 job-level observations uniquely identifying about a 1,200 savings and thrift plans with flat match structures.

In our analysis, the key variables of interest are the match rate, match ceiling, maximum match rate, default contribution rate, default match rate, an autoenrollment indicator, DC costs, and other compensation cost variables (table 1). The maximum match rate is determined by the match rate - the percentage of each dollar of employee contributions that is matched - and the match ceiling - the limit on the percentage of contributions that are matched. Workers who contribute up to the match ceiling receive the maximum employer match. For example, if a 401(k) plan has a match rate of 50 cents per dollar up to a ceiling of 6 percent of pay, the maximum match rate is 3 percent of pay. 
In plans with automatic enrollment, the default contribution rate is the percent of the worker's salary that is deferred if the worker does not select a contribution rate. Following this is the default match rate which is similar to the maximum match rate but computed using the default contribution rate instead of the match ceiling. It is the percent of salary that the employer contributes if a worker remains at the default contribution rate. Some plans with automatic enrollment also have escalating employee default contribution rates. Thus, the default max contribution rate and default max match rate are reached at the end of the escalation.

In the descriptive analysis, we use job-level weights to reflect the percentage of workers in the private sector who have jobs with a DC plan of particular characteristics.

\section{Descriptive Analyses}

\subsection{Prevalence of Automatic Enrollment}

Overall, 14.5 percent of workers in our sample with savings and thrift plans have an automatic enrollment plan feature (figure 1). ${ }^{12}$ This includes between 20 and 25 percent of workers in the agriculture, mining \& construction, wholesale trade, and financial services, insurance \& real estate sectors, but only about 4 percent of workers in retail trade. It also includes about one in five workers employed by large firms with at least 1,000 employees, but only one in eight workers in small firms with less than 500 employees (figure 2).

Table 2 shows the distribution of workers with and without autoenrollment plans by the characteristics of their establishments. Compared with workers without autoenrollment plans, those with automatic enrollment are more likely to be employed: 1) in agricultural, mining \& construction, wholesale trade, and financial services, insurance \& real estate industries; and 2) by companies that have 500 or more employees. Relative to workers without autoenrollment plans, those with automatic enrollment are also in establishments: 1) with larger shares of workers who have DB pensions and are full-time, unionized, and highly paid; and 2) located in metropolitan areas and in the west. For example, 20.3 percent of workers in autoenrolled plans are in the financial services, insurance \& real estate sectors, compared with 14.1 percent of workers in plans without autoenrollment. Also, 43.7 percent of workers in plans with autoenrollment are employed by large establishments (500 or more employees), compared with only 30.3 percent of those in plans without automatic enrollment. Additionally, 17.7 percent of workers in autoenrolled plans are in unionized jobs, compared with only 4.4 percent of those in plans without autoenrollment provisions. Finally, only 4 percent of workers in

firms with autoenrollment have wages in the bottom tercile of the wage distribution, compared with 13.4 percent of their counterparts without automatic enrollment. ${ }^{13}$

\subsection{Differences in Participation and Match Rates by Autoenrollment}

Table 3 compares participation and plan provisions among workers with and without automatic enrollment. Overall, 68.7 percent of workers participate in their employers' plans. Confirming the findings of previous studies, we find that plans with automatic enrollment have higher participation rates than those without this plan feature - 77.1 versus 67.3 percent (Beshears et al. (2009); Choi et al. (2002), (2004); Madrian and Shea (2001)).

The average match rate is 71.1 percent and differs statistically between plans with and without automatic enrollment -65.4 percent versus 72.1 percent, respectively. The average match ceiling is 5 percent of pay and does not differ significantly between workers with and without automatic enrollment. Workers' 
maximum match rate averages 3.5 percent overall and statistically differs between those with and without autoenrollment plans - 3.5 percent for those without autoenrollment compared with 3.2 percent for those with this plan feature. In most industries we examine, average maximum match rates are higher among workers without autoenrollment than those with this provision (figure 3). Differences are especially large for workers in the transportation \& public utilities, and retail trade sectors. In establishments with less than 1,000 employees and those with 2,500-4,999 employees, maximum match rates are also higher among workers without autoenrollment than those with it (figure 4). However, differences are especially large for workers in establishments with less than 500 employees.

DC plan costs depend not only on how much the employer offers to match, but also on how much workers actually contribute. While we know nothing about employees' actual contributions, we do know the default contribution rate of plans with automatic enrollment. Previous literature has shown that workers are slow to move away, if at all, from the defaults once enrolled (Choi et al., 2004). If that is the case, the default contribution rate and the resulting default match rate might get us closer to the actual cost of a DC plan than the maximum match rate would.

The average default contribution rate for workers in autoenrollment plans is 2.8 percent (table 3 ). To receive the maximum match, workers would need to contribute an average of 5.1 percent (the match ceiling). Even with the built-in escalation of the default contribution rate in 22 percent of our plans, the default max contribution rate is 3.4. Thus, on average, firms in our sample are defaulting their workers at a contribution rate at which workers cannot take full advantage of the employer match.

It is informative to examine differences in match structures beyond the mean. Figure 5 compares the distribution of maximum match rates in plans with and without automatic enrollment with the distribution of default match rates and default max match rates. Overall, the distribution of the maximum match rate in plans with automatic enrollment is more skewed towards the left (carries less weight in the right tail) than the distribution in plans without the automatic enrollment feature. The distributions of the default match rate and the default max match rate have even less weight in the right tail. Three-quarters of plans with automatic enrollment have a default match rate and two-thirds have a default max match rate of 2 percent or less of pay; however, less than a third of them have a maximum match rate within that same range. An even a smaller percentage of plans without automatic enrollment have a maximum match rate of 2 percent or less of pay. Thus, in addition to offering lower maximum match rates than plans without autoenrollment, employers with auto-enrollment may be using their default employee contribution rate to help offset the higher costs that come with higher participation rates. By setting default match rates lower than maximum match rates, employers can contribute to the accounts of more workers without necessarily increasing their costs. $^{14}$

\subsection{Understanding How Establishment Costs Vary by Automatic Enrollment}

Wages and benefits are higher among workers in savings and thrift plans with autoenrollment than those without (table 4). Among workers with automatic enrollment, for example, wages average $\$ 27.70$ per labor hour, health insurance benefits average $\$ 3.80$ per labor hour, and total costs average $\$ 40.90$ per labor hour. In contrast, for workers without autoenrollment, wages average $\$ 26$ per labor hour, health insurance benefits average $\$ 2.90$ per labor hour, and total costs average $\$ 37.60$ per labor hour.

Defined contribution plan costs, unlike match rates and autoenrollment provisions, are not specific to particular plans. Instead, these data reflect employer costs accrued at the job level. ${ }^{15}$ For example, DC costs vary by jobs in the establishment, but not by plans within that job - it is an aggregate measure of the cost per hour for providing DC plan(s) to workers on that job. Nonetheless, DC costs should be correlated 
with the maximum match rate, which our results show is significantly lower among autoenrollment plans. ${ }^{16}$ Furthermore, in addition to the employers' matching contributions, DC costs include administrative and other expenses that are likely to be higher in plans with autoenrollment provisions than those without (Andersen et al. (2001)). However, our descriptive statistics show no statistically significant difference between the DC costs of plans with and without automatic enrollment (table 4).

\section{Multivariate Analyses}

The descriptive analyses revealed important differences in employer match rates and compensation by automatic enrollment. In the following sections, we examine whether these relationships still exist after controlling for other factors.

\subsection{Automatic Enrollment, Participation and the Employer Match}

We begin by examining the relationship between automatic enrollment, plan participation, and the generosity of the employer match. We estimate a series of ordinary least squares (OLS) regressions on plan-level data. The key variable of interest in our models is an indicator for whether the plan includes automatic enrollment features. We report robust standard errors, clustered on state level.

Table 5 presents results from an OLS regression of plan participation rates on automatic enrollment. Consistent with other studies, we find that the coefficient on automatic enrollment is positive and highly significant. ${ }^{17}$ Among the savings and thrift plans in our sample, automatic enrollment is associated with 7 percentage points higher participation rates. This result is not particularly surprising since the literature on automatic enrollment has consistently and unambiguously reported strong positive effects of automatic enrollment on participation. However, the literature on the effects of the employer match on participation has produced conflicting results. While most studies have found a strong positive link between participation in a retirement plan and the existence of an employer match, the relationship between participation and the level of the match has not been proven to be particularly strong. For example, Beshears et al. (2010), in a sample of nine firms with automatic enrollment, found that reducing the employer match by 1 percent of pay was associated with a 1.8 to 3.8 percentage point decrease in the plan participation rate at six months of eligibility, and concluded that the presence of an automatic enrollment provision diminishes the need for employers to provide generous matches. In that respect, our results side with the studies that find positive but only weak effects of the employer match itself. We find that the maximum match rate is positively correlated with participation, but its coefficient is small and not statistically different from zero. ${ }^{18}$ Hence, automatic enrollment is a much stronger determinant of participation than the maximum match rate - supporting the hypothesis raised in past studies, namely that the importance of the employer match for stimulating participation weakens in the presence of automatic enrollment (Beshears et al., (2010)). Finally, some plan provisions in the NCS data have been imputed via a statistical match. We control for this using a flag and find that it is not statistically significantly correlated with our dependent variables. ${ }^{19}$

The second column in table 5 shows results from an OLS regression of the relationship between the default match rate and plan participation among plans with automatic enrollment. Although positive, the coefficient on the default match rate is also not statistically different from zero and is much smaller that the coefficient on autoenrollment. This result suggests that another way for employers to keep costs down after implementing automatic enrollment would be to set a relatively low default match rate because it would not negatively affect participation. This finding is also consistent with those of other studies. For example, Nessmith, Utkus, and Young (2007) found that plan quit rates among employees who had been automatically enrolled in their 
employers' retirement plans did not vary in response to the default contribution rate. Other factors positively correlated with participation are the average wage per hour, and the share of full-time workers.

Next we estimate the correlation between automatic enrollment and the maximum match rate, match rate, and match ceiling (table 6). The first column of the table shows results from an OLS regression of employers' maximum match rate. The coefficient on automatic enrollment is negative and statistically significant with a 99 percent confidence level. Controlling for other factors, plans with automatic enrollment have an average maximum match rate that is 0.38 percentage points ( 11 percent of the average) lower than those without an automatic enrollment provision. The next two columns of the table reveal what is driving this result. The coefficient on automatic enrollment is strongly significant and negative in the regression of the match rate, but it is not a significant predictor of the match ceiling. On average, plans with automatic enrollment have a match rate that is 8.2 percentage points (12 percent of the average) lower than plans without the feature.

The coefficients on the other variables generally align with our expectations. Compared with the wholesale trade industry, we find that plans in the financial, insurance \& real estate industries have significantly higher maximum match rates - a result driven entirely by the match rates. For example, the average maximum match rate for these sectors is 1.1 percentage points higher and the average match rate is 15.2 percentage points higher than those in the wholesale trade sector. In addition, establishment size is also positively correlated with employers' match. Plans among establishments with at least 500 employees have an average maximum match rate that is 0.2 percentage points higher and an average match rate that is 4.9 percentage points higher than plans in smaller establishments. However, their match ceilings do not differ significantly. Also, plans among establishments located in metropolitan areas have significantly higher maximum match rates than those in non-metropolitan areas, while those in the south have significantly lower maximum match rates than those in the northeast. To capture the generosity of establishments, we also control for the share of workers with defined benefit plans, the share of full-time workers, and the share of union workers. None of these variables are significantly correlated with the maximum match rate, although some of them are correlated with the match rate and/or the match ceiling.

\subsection{Automatic Enrollment and Total Compensation Costs}

In this section, we consider the relationship between autoenrollment and total employee compensation using a series of OLS regressions. Because the NCS data calculates compensation costs at the job level and because workers at various jobs within the firm often share the same plan, we estimate these equations at the establishment level. The key variable of interest in our models is an indicator for whether there exists at least one savings and thrift plan with automatic enrollment at that establishment. We control for industry, establishment size, share of workers in the plan who also have a DB plan, proportion of full-time and union workers, metropolitan area, and geographic region. We report robust standard errors, clustered on state level.

Table 7 shows the results of an ordinary least squares regression of total employer costs on automatic enrollment. While automatic enrollment is positively correlated with total costs, standard significance tests suggest that its coefficient is not significantly different from zero. The results show also that compared with the wholesale trade sector, firms in transportation \& public utilities have total compensation costs per labor hour which are $\$ 16.50$ higher, followed by those in agriculture, mining \& construction ( $\$ 8.80$ higher), and financial, insurance \& real estate industries ( $\$ 7.80$ higher). Other factors that are positively correlated with total compensation are establishment size, the share of full-time workers, being in a metropolitan area and being in the northeast region. Establishments with more than 5,000 employees have total compensation cost per labor hour that are $\$ 12.60$ higher than establishments with less than 500 employees. Establishments in the Midwest and South regions have total labor costs that are $\$ 14.40$ and $\$ 12.50$ lower than those in the 
Northeast, while those in metropolitan areas have costs of $\$ 6.60$ more on average than those who are not in metropolitan areas.

Next we consider whether the reason there is no statistically significant correlation between autoenrollment and total costs is that a positive correlation with DC costs, but a negative correlation with non-DC costs cancel each other out. To do this, we jointly estimate a number of cost equations in a seemingly unrelated regressions model (SUR), allowing us to test cross-equation restrictions and the possibility that the error terms across equations are contemporaneously correlated. ${ }^{20}$

The second set of regressions in table 7 show the seemingly unrelated regression results for DC costs and non-DC costs. We find no evidence that firms with autoenrollment have DC costs that are different higher or lower - than those without autoenrollment. We also find no evidence that these firms have different non-DC costs, nor any evidence that DC costs crowd out non-DC costs. We cannot reject the hypothesis that the coefficient on automatic enrollment is jointly equal to zero in the two equations, suggesting that neither DC costs nor non-DC costs are related to automatic enrollment once other factors are controlled for. ${ }^{21}$ The results show that establishments where all workers are covered by a DB plan have on average $\$ 4.10$ higher non-DC compensation costs and 22 cents lower DC costs as compared with establishments with no DB covered workers. Larger employee size establishments have on average both higher DC costs, and higher non-DC costs, and so do those in metropolitan areas. Compared with the Northeast region, DC cost per labor hour are 56, 46 and 36 cents lower in the Midwest, the South, and the West regions respectively.

With regard to the share of total compensation that DC costs constitute, we also find no statistically significant difference between firms with and without automatic enrollment. Interestingly, the higher a firm's average total compensation, the more it spends on its DC plans. For example, the DC cost share for firms in the middle quintile of total compensation is 0.6 percentage points higher than for firms in the bottom quintile; and it is 1.7 percentage points higher for firms in the top quintile than for those in the bottom quintile.

Table 8 shows the seemingly unrelated regression results for various employer costs. We group the costs into the following categories: defined contribution plans, wages, legal (Social Security, Medicare, state/federal unemployment insurance, and workers' compensation), health insurance, defined benefit pensions, leave (vacation, holidays, sick leave, and other leave), insurance (life insurance and short-term and long-term disability insurance), and other costs (non-production bonuses, severance pay, and supplemental unemployment insurance). Again, there is no evidence that firms with and without autoenrollment have different DC costs, or that DC costs crowd out other forms of employer compensation. However, autoenrollment is associated with higher costs for health insurance (31 cents) and leave benefits (27 cents), and lower costs for defined benefit pensions (17 cents). A significance test rejects the null hypothesis that the coefficients on automatic enrollment across equations are jointly equal to zero $(p<.05)$. Many of the coefficients have the expected signs. In general, costs per labor hour increase with establishment size and the percentage of full-time workers. All categories of employer costs, but DB costs and other costs, are higher in metropolitan areas than in non-metropolitan areas. All employer costs, but DB costs are lowest in the Midwest region, followed by South, West, and Northeast regions. There are statistically significant differences in DB costs per labor hour across regions.

All employer costs are highest in the Northeast and lowest in non-metropolitan areas and the Midwest. Interestingly, the share of union workers in an establishment is positively correlated with costs associated with legal requirements, health insurance, and other insurance, but is not a significant predictor of the costs for DC plans, wages, DB pensions, or leave. Establishments with a 100 percent of their workers unionized have on average $\$ 2.40$ higher health insurance, 31 cents higher legal, and 10 cents higher insurance costs per labor hour compared with establishments with no unionized workers. Almost across the board, transportation \& public utilities sectors have the highest employer costs. 
Finally, the larger the share of workers covered by a DB plan, the lower the average DC costs, as these types of benefits are close substitutes. Establishments where all workers are covered by a DB plan have, on average, DC costs that are 32 cents lower per labor hour and DB costs that are $\$ 2.30$ higher per labor hour, compared with establishments with no DB covered workers. However, the share of workers with DB plans and the share of workers with another DC plan are positively correlated with a number of employer benefits. A possible explanation for this finding is that establishments with large shares of workers with DB plans or multiple DC plans pay higher total compensation, on average, to attract and retain more productive workers. $^{22}$

\section{Discussion}

Our models, particularly those looking at establishment costs, likely remind the reader of the empirical models typically found in the compensating differentials literature. As Rosen $(\sqrt{1986}))$ summarized it, the theory of equalizing differences implies that otherwise identical employees who receive higher fringe benefits should be paid a lower wage. Previous studies that have tried to test this theory with respect to pension benefits, however, often fail to find evidence for a compensating differential. The lack of accurate data on workers' productivity often leads to omitted variable bias in empirical specifications and is considered to be the likely driver behind the observed positive correlation between wages and pension benefits in the data.

Since we are also not able to control for workers' innate ability, unobserved worker productivity traits can potentially cause an omitted variable bias in our estimation as well. However, we believe their confounding effects in our specification are much smaller for the following three reasons. First, we focus our analysis only on compensation packages that already include a pension plan. Thus, our analysis includes only individuals who have self-selected into pension jobs and are arguably more comparable to each other than to workers in non-pension jobs. Second, our analysis does not look for compensating differences between wage and nonwage benefits, but rather examines whether total compensation and its components depend on the structure of the pension plan (i.e. the presence of automatic enrollment). And third, in contrast to the compensating differentials literature, which suggests a negative relationship between wage and non-wage benefits, it is more difficult to rationalize why a worker would be willing to give up compensation in order to be automatically enrolled. Thus, we expected the correlation between autoenrollment and total compensation to be zero, or positive if automatic enrollment increases productivity. Even if there is unobservable workers' self-selection of the type suggested by the compensating differentials literature, we would expect it to bias our results upward. ${ }^{23}$ Thus, the estimated coefficients on automatic enrollment in the regressions of compensation costs can be considered a conservative upper bound and makes us conclude that there is no evidence of statistically significant differences in total compensation costs or DC plan costs between DC plans with and without automatic enrollment.

However, we did find significant differences in the components of DC costs. Using nationally representative data, we confirmed previous case study results that automatic enrollment is associated with higher plan participation rates -7 percentage points on average. We also find that plans with the automatic enrollment feature offer on average 0.38 lower maximum matches to their employees. Given an average wage of $\$ 26.20$, average participation rate of 68.7 percent, and an average maximum match of 3.2 percent in our sample, a back-of-the-envelope calculation shows that the 0.38 percentage point lower match rate translates into a savings of roughly 7 cents per labor hour. These savings of 7 cents per labor hour almost completely offset the additional costs of 6.5 cents resulting from higher participation rates. Given the finding of no significant correlation between wages and automatic enrollment (table 8), this is consistent with our earlier result of no significant difference in DC plan costs with respect to autoenrollment. Instead, the cross-sectional evidence from the NCS suggests that in order to adapt to higher per-worker cost from autoenrollment, firms might be making adjustments only within the DC portion of their compensation packages. 
Our descriptive analysis also showed that default contribution rates in autoenrollment plans are set at levels that do not take full advantage of the employer match. The roughly offsetting effects of higher participation rates and lower matches, makes us believe that in our sample of plans, the defaults have only a weak contribution to the total difference in costs. However, information on the actual employee contributions and how they differ from the defaults is needed in order to quantify correctly the contribution of this factor to the total difference in costs. This is an interesting avenue for future research.

\section{Conclusion}

Most pension-related research has focused on individuals' behavior - whether workers participate in a 401(k), how much they contribute, and how they make investment choices. Even the discussion surrounding automatic enrollment has focused on how it benefits employees by increasing their pension coverage and ultimately their retirement savings. Relatively little is known about employer decisions regarding retirement plans, yet employer actions surrounding these plans substantially affect future retirement security. By boosting plan participation, automatic enrollment likely increases employer costs as previously unenrolled workers receive matching retirement plan contributions. Standard economic theory suggests that this is likely not the end of the story as profit-maximizing employers might readjust their compensation packages to equate labor's compensation with labor's productivity.

Using cross-sectional variation in plan features and costs, derived from the restricted-access employerlevel National Compensation Survey, this paper empirically examines the relationship between automatic enrollment and firms' DC plan match structure, DC plan costs, and total compensation. We find that employer match rates are negatively and significantly correlated with autoenrollment. The maximum match rate averages 3.5 percent for plans without automatic enrollment, but only 3.2 percent for those with automatic enrollment. Even controlling for other factors, we find that automatic enrollment is associated with a 0.38 percentage point (11 percent) lower maximum match rate. Looking just at workers in plans with an autoenrollment provision, the default contribution rate averages only 2.8 percent (3.4 percent with full autoescalation). Yet to receive the maximum match, these workers would need to contribute an average of 5.1 percent. So employers with autoenrollment plans are setting the default contribution rate well below the rate needed for the maximum match. This allows them to contribute to the accounts of more workers without necessarily increasing their costs. Our findings suggest that employers might be doing exactly this, since we find no evidence that total costs differ between firms with and without automatic enrollment even though automatic enrollment is associated with a 7 percentage point higher plan participation rate. Furthermore, we find no evidence that DC costs crowd out other forms of employer compensation - suggesting that firms might be lowering their maximum match rates and default match rates enough to completely offset the higher costs of automatic enrollment without needing to reduce other compensation costs.

\section{References}

Adams, N.. (2011) Points of Hue:PLANSPONSOR's 2011 Annual Defined Contribution Survey.PLANSPONSOR Magazine November.

Andersen, M., Atlee, S., . Cardamone, D., Danaher, B. and Utkus, S. (2001) Automatic Enrollment: Benefits and Costs of Adoption. Valley Forge, PA: The Vanguard Center for Retirement Research.

Atchison, Amy. (2010) Survey Findings: Hot Topics in Retirement 2010. Lincolnshire, IL: Hewitt Associates LLC.

Beshears, J., Choi, J. J., Laibson, D. and Madrian, B. C. (2009) The Importance of Default Options for Retirement Savings Outcomes: Evidence from the United States. In Social Security Policy in a Changing Environment, University of Chicago Press.

Beshears, J., Choi, J. J., Laibson, D. and Madrian, B. C. (2010) The Impact of Employer Matching on Savigns 
Plan Participation under Automatic Enrollment. In Research Findings in the Economics of Aging, University of Chicago Press.

Brady, P. J. (2007) Pension Nondiscrimination Rules and the Incentive to Cross Subsidize Employees. Journal of Pension Economics and Finance 6(2): 127-45.

Bruno, M. (2008) Cost of 401(k) Match Limits Use of Autoenrollment. Investment News. March 17.

Choi, J. J., Laibson, D. and Madrian, B. C. (2004) Plan Design and 401(k) Savings Outcomes. National Tax Journal 57: 275-298.

Choi, J. J., Laibson, D., Madrian, B. C. and Metrick, A. (2002) Defined Contribution Pensions: Plan Rules, Participant Decisions, and the Path of Least Resistance. In Tax Policy and the Economy Volume 16, edited by James Poterba (pp. 67-114). Cambridge, MA: MIT Press.

Choi, J. J., Laibson, D., Madrian, B. C. and Metrick, A. (2004) For Better or For Worse: Default Effects and 401(k) Savings Behavior. In Perspectives in the Economic of Aging, edited by David A. Wise (81-121). Chicago, IL: University of Chicago Press.

Dworak-Fisher, K. (2007) Employer Generosity in Employer-Matched 401(k) Plans, 2002-03. Monthly Labor Review 130(9): 11-19.

Dworak-Fisher, K. (2008) Encouraging Participation in 401(k) Plans: Reconsidering the Employer Match. BLS Working Paper 420. Washington, DC: U.S. Department of Labor.

Dworak-Fisher, K. (2011) Matching Matters in 401(k) Plan Participation. Industrial Relations: A Journal of Economy and Society, 50:713-737

Engelhardt, G. V. (2011) State Wage-Payment Laws, the Pension Protection Act of 2006, and 401(k) Saving Behavior. Economics Letters 113: 237-40.

Engelhardt, G. V. and Kumar, A. (2007) Employer Matching and 401(k) Saving: Evidence from the Health and Retirement Study. Journal of Public Economics, vol. 91(10), pp. 1920-1943.

Even, W. E. and Macpherson, D. A. (2005) The Effect of Employer Matching in 401(k) Plans. Industrial Relations 44(3): 525-49.

Gustman, A. L. and Steinmeier, T. L. (2004) What People Dont Know About Their Pensions and Social Security. In Private Pensions and Public Policies, edited by William G. Gale, John B. Shoven and Mark J. Warshawsky, ( 525-549). Washington, D.C.: Brookings Institution.

Hess, P. and Xu, Y. (2011) 2011 Trends and Experiences in Defined Contribution Plans: Paving the Road to Retirement. Aon Hewitt.

Holmer, M., Janney, A. and Cohen, B. (2012) Pensim Overvew. Mimeo, U.S. Department of Labor, EBSA, Office of Policy and Research, September 2012. http://www.polsim.com/doc/overview.pdf

Karamcheva, N. and Sanzenbacher, G. (2013) Bridging the Gap in Pension Participation: How Much Can Universal Tax-Deferred Pension Coverage Hope to Achieve?, IZA Discussion Paper \#7518.

Karamcheva, N. and Sanzenbacher, G. (2010) Is Pension Inequality Growing? Issues in Brief, Center for Retirement Research, IB \#10-1.

Madrian, B. C. and Shea, D. F. (2001) The Power of Suggestion: Inertia in 401(K) Participation and Savings Behavior. The Quarterly Journal of Economics 116(4):1149-87.

Nessmith, W. E. Utkus, S. P. and Young, J. A. (2007) Measuring the Effectiveness of Automatic Enrollment. Valley Forge, PA: The Vanguard Center for Retirement Research.

O'Hare, B. F. and Amendola, D. (2007) Pension Protect Act: Automatic Enrollment Plans. New York Law Journal 237: 104 .

Plan Sponsor Council of America (2011) 54th Annual Survey. PSCA's Annual Survey of Profit Sharing and 401(k) Plans.

Plan Sponsor Council of America (2012) 55th Annual Survey. PSCA's Annual Survey of Profit Sharing and 401(k) Plans.

Patterson, M. P., Veal, T. and Wray, D. L. (2006) The Pension Protection Act of 2006: Essential Insights. Washington, DC: Thompson Publishing Group.

Purcell, P. (2007) Automatic Enrollment in 401(k) Plans. No. RS21954. Washington, DC: Congressional Research Service.

Rosen, S. (1986) The Theory of Equilizing Differences. In Handbook of Labor Economics Volume 1, edited by O. Ashenfelter and R. Layards (pp. 641-692). Amsterdam: North-Holland.

Sandler, S., Cole, S. and Green, R. (2011) Annual 401(k) Survey: Retirement Readiness. New York, NY: Deloitte Development LLC. 
Soto, M. and Butrica, B. A. (2009) Will Automatic Enrollment Reduce Employer Contributions to 401(k) Plans? Washington, DC: Urban Institute.

U.S. Bureau of Labor Statistics (2012a) Chapter 8 National Compensation Methods. In BLS Handbook of Methods http://www.bls.gov/opub/hom/pdf/homch8.pdf.

U.S. Bureau of Labor Statistics (2012b) National Compensation Survey: Employee Benefits in the United States, March 2012. Washington, DC: U.S. Department of Labor. http://www.bls.gov/ncs/ebs/benefits/2012/ebbl0050.pdf.

VanDerhei, J. (2010) The Impact of Automatic Enrollment in 401(k) Plans on Future Retirement Accumulations: A Simulation Study Based on Plan Design Modifications of Large Plan Sponsors. Issue Brief No. 341. Washington, DC: Employee Benefit Research Institute.

Wiatrowski, W. J. (2011) Changing Landscape of Employer-Based Retirement Benefits. Compensation and Working conditions Online. Washingtion, DC: U.S. Department of Labor. http://www.bls.gov/opub/cwc/print/cm20110927ar01p1.htm.

Zellner, A. (1962) An Efficient Method of Estimating Seemingly Unrelated Regressions and Tests for a Regression Bias Journal of American Statistical Association 57: 348-368. 
Table 1. Variables

Generosity Measure Unit of Measurement. Definition

Plan Provisions

Match rate

Integer from 0 to 100

The percentage of each dollar of employee contributions that is matched (e.g 50 cents on the dollar or 50 percent).

Match ceiling

Maximum match rate

Default contribution rate

Default match rate

Default max contribution rate

Default max match rate
Integer from 0 to 100

Integer from 0 to 100

The limit on the percentage of employee contributions that is matched (e.g. employee's contribution is matched up to 6 percent of pay).

Maximum employer's contribution as a percentage of salary. Alternatively, the percentage of salary that the employer would contribute if the employee contributed enough to exhaust the employer's match offer. This is computed as: (match rate*match ceiling)/100.

Integer from 0 to 100 In plans with automatic enrollment, the default employee contribution percentage.

Integer from 0 to 100 This is computed as: (match rate*default contribution rate)/100.

Integer from 0 to 100 In plans with automatic enrollment, the default employee contribution percentage at the end of the escalation process.

Integer from 0 to 100 This is computed as: (match rate*default max contribution rate) $/ 100$.

Employer Average Cost for Providing Benefits to Workers in a Given Job (from ECEC data)

$\begin{array}{ll}\text { DC cost } & \text { \$ per labor hour } \\ \text { Wages } & \text { \$ per labor hour } \\ \text { Health insurance costs } & \text { \$ per labor hour } \\ \text { Legal costs } & \$ \text { per labor hour }\end{array}$

Leave costs

Insurance costs

Other costs
$\$$ per labor hour

$\$$ per labor hour

$\$$ per labor hour
Includes all DC plans.

Includes wages.

Includes health insurance.

Includes Social Security, Medicare, state/federal unemployment insurance, and worker's compensation.

Includes vacation, holidays, sick leave, and other leave to workers in a given job.

Includes life insurance and short-term and long-term disability.

Include non-production bonuses, severance pay, and supplemental unemployment insurance. 
Table 2. Distribution of Workers in Savings \& Thrift Plans With and Without Autoenrollment by Establishment Characteristics

\begin{tabular}{|c|c|c|c|c|}
\hline & All & $\begin{array}{c}\text { Without } \\
\text { autoenrollment }\end{array}$ & $\begin{array}{c}\text { With } \\
\text { autoenrollment }\end{array}$ & \\
\hline Autoenrollment & $14.5 \%$ & & & \\
\hline \multicolumn{5}{|l|}{ Industry } \\
\hline Agriculture, mining and construction & $4.0 \%$ & $3.5 \%$ & $6.7 \%$ & $* * *$ \\
\hline Manufacturing & $15.0 \%$ & $14.6 \%$ & $17.1 \%$ & * \\
\hline Transportation and public utilities & $4.3 \%$ & $4.1 \%$ & $5.0 \%$ & \\
\hline Wholesale trade & $6.4 \%$ & $5.7 \%$ & $10.3 \%$ & $* * *$ \\
\hline Retail trade & $7.6 \%$ & $8.5 \%$ & $1.9 \%$ & $* * *$ \\
\hline Financial, insurance and real estate & $15.0 \%$ & $14.1 \%$ & $20.3 \%$ & $* * *$ \\
\hline Other services & $47.9 \%$ & $49.4 \%$ & $38.7 \%$ & $* * *$ \\
\hline \multicolumn{5}{|l|}{ Size } \\
\hline$<500$ & $67.8 \%$ & $69.7 \%$ & $56.3 \%$ & $* * *$ \\
\hline $500-999$ & $14.0 \%$ & $13.4 \%$ & $17.3 \%$ & $* * *$ \\
\hline $1,000-2,499$ & $10.2 \%$ & $9.5 \%$ & $14.8 \%$ & $* * *$ \\
\hline $2,500-4,999$ & $4.7 \%$ & $4.3 \%$ & $6.7 \%$ & $* *$ \\
\hline $5,000+$ & $3.4 \%$ & $3.1 \%$ & $4.9 \%$ & $* *$ \\
\hline Share of workers with DB plan & $24.4 \%$ & $23.1 \%$ & $31.6 \%$ & $* * *$ \\
\hline Share of full-time workers & $89.0 \%$ & $88.1 \%$ & $94.1 \%$ & $* * *$ \\
\hline Share of union workers & $6.4 \%$ & $4.4 \%$ & $17.7 \%$ & $* * *$ \\
\hline \multicolumn{5}{|l|}{ Wages (tercile) } \\
\hline Bottom & $12.0 \%$ & $13.4 \%$ & $4.0 \%$ & $* * *$ \\
\hline Middle & $34.0 \%$ & $33.7 \%$ & $35.9 \%$ & \\
\hline Top & $54.0 \%$ & $52.9 \%$ & $60.1 \%$ & $* * *$ \\
\hline Metropolitan area & $91.1 \%$ & $90.5 \%$ & $94.8 \%$ & $* * *$ \\
\hline \multicolumn{5}{|l|}{ Region } \\
\hline Northeast & $20.9 \%$ & $21.6 \%$ & $16.8 \%$ & $* * *$ \\
\hline Midwest & $20.5 \%$ & $20.3 \%$ & $21.5 \%$ & \\
\hline South & $36.9 \%$ & $37.5 \%$ & $33.3 \%$ & ** \\
\hline West & $21.7 \%$ & $20.6 \%$ & $28.3 \%$ & $* * *$ \\
\hline
\end{tabular}

Source: Authors' calculations from U.S. Bureau of Labor Statistics, National Compensation Survey (NCS) restricted-use microdata extract, 20-11.

Notes: Sample includes savings and thrift plans with flat employer match structures. Job-level weights are used to reflect the percentage of workers in the population. Statistical difference between those without and with autoenrollment is denoted by ${ }^{*} \mathrm{p}<.10,{ }^{* *} \mathrm{p}<.05$, and ${ }^{* * *} \mathrm{p}<.01$. 
Table 3. Participation and Plan Provisions Among Workers in Savings \& Thrift Plans by Autoenrollment

\begin{tabular}{|c|c|c|c|c|c|c|c|}
\hline & \multicolumn{2}{|c|}{ All } & \multicolumn{2}{|c|}{$\begin{array}{l}\text { Withou } \\
\text { autoenrollment }\end{array}$} & \multicolumn{2}{|c|}{$\begin{array}{l}\text { With } \\
\text { autoenrollment }\end{array}$} & \\
\hline & Mean & St. dev & Mean & St. dev & Mean & St. dev & \\
\hline Participation rate & 68.7 & 26.0 & 67.3 & 26.2 & 77.1 & 23.3 & $* * *$ \\
\hline Maximum match rate & 3.5 & 1.7 & 3.5 & 1.7 & 3.2 & 1.4 & $* * *$ \\
\hline Match rate & 71.1 & 31.8 & 72.1 & 32.3 & 65.4 & 28.3 & $* * *$ \\
\hline Match ceiling & 5.0 & 1.4 & 5.0 & 1.5 & 5.1 & 1.2 & \\
\hline Default contribution rate & & & & & 2.8 & 1.1 & \\
\hline $\begin{array}{l}\text { Default max contribution } \\
\text { rate }\end{array}$ & & & & & 3.4 & 1.7 & \\
\hline
\end{tabular}

Source: Authors' calculations from U.S. Bureau of Labor Statistics, National Compensation Survey (NCS) restricted-use microdata extract, 20-11.

Notes: Sample includes savings and thrift plans with flat employer match structures. Job-level weights are used to reflect the percentage of workers in the population. Statistical difference between those without and with autoenrollment is denoted by $* \mathrm{p}<.10,{ }^{* *} \mathrm{p}<.05$, and $* * *$ $\mathrm{p}<.01$. 
Table 4. Average Wages and Benefits of Workers in Savings \& Thrift Plans by Autoenrollment

\begin{tabular}{lcccl} 
& All & $\begin{array}{c}\text { Without } \\
\text { autoenrollment }\end{array}$ & $\begin{array}{c}\text { With } \\
\text { autoenrollment }\end{array}$ & \\
\hline DC costs & $\$ 1.2$ & $\$ 1.2$ & $\$ 1.1$ & \\
Total non-DC costs & $\$ 36.9$ & $\$ 36.4$ & $\$ 39.7$ & $* * *$ \\
Total costs & $\$ 38.0$ & $\$ 37.6$ & $\$ 40.9$ & $* * *$ \\
Wages & $\$ 26.2$ & $\$ 26.0$ & $\$ 27.7$ & $* *$ \\
Defined benefit & $\$ 0.5$ & $\$ 0.5$ & $\$ 0.6$ & $* * *$ \\
Health insurance & $\$ 3.0$ & $\$ 2.9$ & $\$ 3.8$ & $* *$ \\
Leave & $\$ 3.1$ & $\$ 3.1$ & $\$ 3.4$ & $* * *$ \\
Insurance & $\$ 0.2$ & $\$ 0.2$ & $\$ 0.2$ & $* * *$ \\
Legal & $\$ 2.8$ & $\$ 2.7$ & $\$ 2.9$ & \\
Other & $\$ 1.0$ & $\$ 1.0$ & $\$ 1.1$ & \\
\hline
\end{tabular}

Source: Authors' calculations from U.S. Bureau of Labor Statistics, National Compensation Survey (NCS) restricted-use microdata extract, 2010-11.

Notes: Sample includes savings and thrift plans with flat employer match structures. Job-level weights are used to reflect the percentage of workers in the population. Statistical difference between those without and with autoenrollment is denoted by ${ }^{*} \mathrm{p}<.10,{ }^{* *} \mathrm{p}<.05$, and $* * *$ $\mathrm{p}<.01$. 
Table 5. OLS Estimates of the Relationship between Participation Rate and Automatic Enrollment

\begin{tabular}{lll}
\hline & Model 1 & Model2 \\
\hline Maximum match & & \\
Default match Rate & 0.161 & \\
Autoenrollment & & 0.812 \\
Industry (omitted=Wholesale trade) & & \\
Agriculture, mining \& construction & $-7.880^{* * *}$ & \\
Manufacturing & $-3.927^{*}$ & -5.955 \\
Transportation \& public utilities & -1.993 & 9.909 \\
Retail trade & -3.380 & $14.201^{* *}$ \\
Financial, insurance \& real estate & 1.745 & 5.171 \\
Other services & $-4.460^{*}$ & 1.481 \\
Size of 500 or more participants & -0.530 & -3.309 \\
Share of workers with DB plan & 1.229 & 3.623 \\
Share of full-time workers & $18.202^{* * *}$ & 6.282 \\
Share of union workers & 2.846 & -2.080 \\
Average wage per hour & $0.226^{* * *}$ & $0.219^{* * *}$ \\
Metropolitan area & -3.888 & -5.571 \\
Region (omitted=Northeast) & & \\
Midwest & $-3.707^{*}$ & $-8.028^{* *}$ \\
South & -0.813 & -5.646 \\
West & $-3.111^{*}$ & -4.216 \\
Flag for imputed participation & $-3.577^{* *}$ & $-7.548^{* * *}$ \\
Flag for imputed plan & 4.542 & 1.911 \\
Constant & $54.264^{* * *}$ & $76.715^{* * *}$ \\
Adjusted R-squared & 0.123 & 0.138 \\
\hline
\end{tabular}

Source: Authors' calculations from U.S. Bureau of Labor Statistics, National Compensation Survey (NCS) restricted-use microdata extract, 2010-11.

Notes: Sample includes savings and thrift plans with flat employer match structures. Significance is denoted by $* \mathrm{p}<.10,{ }^{* *} \mathrm{p}<.05$, and ${ }^{* * *} \mathrm{p}<.01$. 
Table 6. OLS Estimates of the Relationship between Match Rates and Automatic Enrollment

\begin{tabular}{llll}
\hline & & & \\
& $\begin{array}{l}\text { Y=Maximum } \\
\text { match rate }\end{array}$ & $\begin{array}{l}\text { Y=Match } \\
\text { rate }\end{array}$ & $\begin{array}{l}\text { Y=Match } \\
\text { ceiling }\end{array}$ \\
\hline & & & \\
Autoenrollment & $-0.380^{* * *}$ & $-8.262^{* * *}$ & 0.013 \\
Industry (omitted=Wholesale trade) & & & \\
Agriculture, mining \& construction & -0.206 & -0.767 & -0.155 \\
Manufacturing & 0.322 & -3.939 & $0.462^{*}$ \\
Transportation \& public utilities & 0.334 & 6.909 & -0.152 \\
Retail trade & 0.358 & $18.691^{* *}$ & $-0.772^{* * *}$ \\
Financial, insurance \& real estate & $1.088^{* * *}$ & $15.173^{* *}$ & 0.123 \\
Other services & -0.018 & 1.658 & $-0.500^{* * *}$ \\
Size of 500 or more participants & $0.206^{*}$ & $4.902^{* *}$ & -0.113 \\
Share of workers with DB plan & 0.086 & $-4.344^{*}$ & $0.344^{* * *}$ \\
Share of full-time workers & -0.223 & 1.028 & $-0.249^{* *}$ \\
Share of union workers & -0.183 & -2.400 & 0.090 \\
Metropolitan area & $0.263^{*}$ & -2.662 & $0.430^{* * *}$ \\
Region (omitted=Northeast) & & & \\
Midwest & -0.147 & -1.923 & -0.121 \\
South & $-0.276^{*}$ & -4.258 & -0.074 \\
West & 0.071 & -0.577 & 0.159 \\
Flag for imputed plan & -0.111 & -3.041 & -0.025 \\
Constant & $3.426^{* * *}$ & $74.797^{* * *}$ & $5.030^{* * *}$ \\
Adjusted R-squared & 0.082 & 0.071 & 0.083 \\
\hline
\end{tabular}

Source: Authors' calculations from U.S. Bureau of Labor Statistics, National Compensation Survey (NCS) restricted-use microdata extract, 2010-11.

Notes: Sample includes savings and thrift plans with flat employer match structures. Significance is denoted by $* \mathrm{p}<.10,{ }^{* *} \mathrm{p}<.05$, and ${ }^{* * *} \mathrm{p}<.01$. 
Table 7. Seemingly Unrelated Regression Results of Establishment Costs on Automatic Enrollment

\begin{tabular}{|c|c|c|c|c|c|}
\hline & $\begin{array}{l}\mathrm{Y}=\text { Total } \\
\text { costs }\end{array}$ & $\begin{array}{l}\mathrm{Y}=\mathrm{DC} \\
\text { costs }\end{array}$ & $\begin{array}{l}\mathrm{Y}=\text { Non- } \\
\mathrm{DC} \\
\text { costs }\end{array}$ & $\begin{array}{l}\mathrm{Y}=\mathrm{DC} \\
\text { cost } \\
\text { share }\end{array}$ & $\begin{array}{l}\mathrm{Y}=\mathrm{DC} \\
\text { cost } \\
\text { share }\end{array}$ \\
\hline & & & & Model 1 & Model 2 \\
\hline Autoenrollment & 1.418 & 0.028 & 1.337 & 0.001 & 0.001 \\
\hline \multicolumn{6}{|l|}{ Industry (omitted $=$ Wholesale trade) } \\
\hline Agriculture, mining \& construction & $8.831^{* * *}$ & 0.266 & $8.531^{* * *}$ & 0.003 & -0.001 \\
\hline Manufacturing & 1.032 & -0.022 & 1.159 & -0.002 & -0.002 \\
\hline Transportation \& public utilities & $16.506^{* * *}$ & $0.921^{* * *}$ & $15.559^{* * *}$ & $0.007^{* *}$ & 0.003 \\
\hline Retail trade & -3.209 & 0.023 & -3.146 & 0.003 & $0.005^{* *}$ \\
\hline Financial, insurance \& real estate & $7.790^{* *}$ & $0.493^{* * *}$ & $7.391^{* *}$ & $0.009^{* * *}$ & $0.007^{* * *}$ \\
\hline Other services & 3.343 & $0.281^{*}$ & 3.110 & $0.004^{* *}$ & 0.003 \\
\hline \multicolumn{6}{|l|}{ Size $($ omitted $=<500)$} \\
\hline $500-999$ & 0.769 & 0.115 & 0.639 & 0.002 & 0.001 \\
\hline $1000-2499$ & $3.686^{*}$ & $0.312^{* *}$ & $3.431^{*}$ & $0.004^{* *}$ & 0.002 \\
\hline $2500-4999$ & $9.085^{* *}$ & $0.298^{* *}$ & $8.841^{* * *}$ & 0.003 & 0.001 \\
\hline $5000+$ & $12.587^{* * *}$ & $0.543^{* * *}$ & $12.124^{* * *}$ & 0.003 & 0.000 \\
\hline Share of workers with DB plan & $3.755^{* *}$ & $-0.226^{* * *}$ & $4.082^{* *}$ & $-0.005^{* * *}$ & $-0.007 * * *$ \\
\hline Share of workers with health benefits & -1.198 & 0.040 & -1.019 & 0.003 & 0.004 \\
\hline Share of workers with leave & -0.194 & -0.266 & -0.181 & $-0.011^{* *}$ & $-0.011^{* *}$ \\
\hline Share of workers with insurance benefit & $6.336^{* * *}$ & $0.372^{* *}$ & $6.084^{*}$ & $0.007 * * *$ & $0.004^{*}$ \\
\hline Share of workers with other costs & $7.035^{* * *}$ & $0.257^{* * *}$ & $6.764^{* * *}$ & 0.002 & 0.000 \\
\hline Has other DC plan & $2.381^{* *}$ & $0.330^{* * *}$ & 2.027 & $0.006^{* * *}$ & $0.005^{* * *}$ \\
\hline Share of full-time workers & $15.192^{* * *}$ & $0.587^{* * *}$ & $14.349^{* * *}$ & $0.006^{*}$ & 0.001 \\
\hline Share of union workers & 0.770 & 0.091 & 0.607 & 0.000 & -0.001 \\
\hline Metropolitan area & $6.606^{* * *}$ & $0.450 * * *$ & $6.208^{* * *}$ & $0.006^{* * *}$ & $0.004^{* * *}$ \\
\hline \multicolumn{6}{|l|}{ Region (omitted = Northeast) } \\
\hline Midwest & $-14.408^{* * *}$ & $-0.556^{* * *}$ & $-13.854^{* * *}$ & $-0.005^{* * *}$ & -0.002 \\
\hline South & $-12.491^{* *}$ & $-0.458^{* *}$ & $-12.101^{* * *}$ & $-0.003^{*}$ & -0.001 \\
\hline West & -8.050 & $-0.362^{* * *}$ & $-7.695^{* * *}$ & $-0.004^{* * *}$ & $-0.003^{* *}$ \\
\hline Flag for imputed costs & 0.139 & -0.092 & -1.274 & 0.001 & 0.001 \\
\hline \multicolumn{6}{|c|}{ Total costs quintile (omitted = bottom) } \\
\hline Second & & & & & 0.001 \\
\hline Middle & & & & & $0.006^{*}$ \\
\hline Fourth & & & & & $0.012^{* * *}$ \\
\hline Top & & & & & $0.017^{* * *}$ \\
\hline Constant & $10.660^{*}$ & -0.118 & $12.068^{*}$ & $0.012^{* *}$ & $0.013^{* *}$ \\
\hline R-squared & 0.277 & 0.227 & 0.272 & 0.173 & 0.238 \\
\hline
\end{tabular}

Source: Authors' calculations from U.S. Bureau of Labor Statistics, National Compensation Survey (NCS) restricted-use microdata extract, 2010-2011.

Notes: Sample includes savings and thrift plans with flat employer match structures. Significance is denoted by $* \mathrm{p}<.10$, $* * \mathrm{p}<.05$, and $* * * \mathrm{p}<.01$. Breusch-Pagan test of independence: chi $2=296.060, \operatorname{Pr}=0.0000$. Joint test of significance of autoenrollment: $\operatorname{chi} 2=0.83, \mathrm{Pr}=0.6595$. 
Table 8. Seemingly Unrelated Regression Results of Establishment Costs on Automatic Enrollment

$\begin{array}{lllllll}\mathrm{Y}=\mathrm{DC} & \mathrm{Y}=\text { Wages } & \mathrm{Y}=\text { Legal } \\ \text { costs }\end{array}$

\begin{tabular}{|c|c|c|c|c|c|c|c|c|}
\hline $\begin{array}{l}\text { Autoenrollment } \\
\text { Industry (omitted }=\text { Wholesale } \\
\text { trade) }\end{array}$ & 0.030 & 0.875 & 0.072 & $0.308^{* * *}$ & $-0.171^{* *}$ & $0.266^{*}$ & 0.013 & 0.173 \\
\hline Manufacturing & -0.023 & 0.207 & 0.185 & $0.549 * *$ & 0.021 & 0.291 & 0.025 & 0.138 \\
\hline Transportation \& public utilities & $0.888^{* * *}$ & $9.751^{* * *}$ & $1.158^{* * *}$ & $1.531^{* * *}$ & $1.137^{* * *}$ & $1.804^{* * *}$ & $0.133^{* * *}$ & 0.156 \\
\hline Retail trade & -0.035 & -2.439 & $-0.351^{*}$ & -0.359 & -0.290 & -0.387 & -0.039 & -0.093 \\
\hline Other services & 0.264 & 2.465 & 0.097 & $0.490^{* *}$ & -0.128 & $0.589^{*}$ & 0.002 & -0.771 \\
\hline \multicolumn{9}{|l|}{ Size $($ omitted $=<500)$} \\
\hline $500-999$ & 0.147 & 0.439 & 0.047 & $0.320 * *$ & -0.153 & 0.313 & 0.0428 & 0.035 \\
\hline $1000-2499$ & $0.339 * * *$ & $2.465^{* * *}$ & $0.198^{* *}$ & $0.447^{* * *}$ & -0.113 & $0.649 * * *$ & $0.087^{* * *}$ & 0.067 \\
\hline $2500-4999$ & $0.369 * * *$ & $5.196^{* * *}$ & $0.394^{* * *}$ & $0.287^{*}$ & 0.084 & $1.247^{* * *}$ & $0.074^{* * *}$ & $3.234^{* * *}$ \\
\hline $5000+$ & $0.577^{* * *}$ & $7.341^{* * *}$ & $0.565^{* * *}$ & $0.541 * * *$ & 0.185 & $1.425^{* * *}$ & $0.058^{* *}$ & $3.235^{* *}$ \\
\hline Share of workers with DB plan & $-0.317^{* * *}$ & 1.570 & $0.174^{*}$ & 0.267 & $2.296^{* * *}$ & $0.591^{* * *}$ & $0.047^{* *}$ & 0.375 \\
\hline Share of full-time workers & $0.829^{* * *}$ & $\begin{array}{l}13.286 \\
* * *\end{array}$ & $0.992^{* * *}$ & $1.558 *$ & 0.037 & $2.061^{* * *}$ & $0.139^{* * *}$ & 0.668 \\
\hline Share of union workers & 0.076 & -1.377 & $0.310^{* *}$ & $2.043 * *$ & -0.025 & 0.010 & $0.100 * * *$ & -1.279 \\
\hline \multicolumn{9}{|l|}{$\begin{array}{l}\text { Region } \\
\text { (omitted=Northeast) }\end{array}$} \\
\hline Midwest & $\begin{array}{l}-0.568 \\
* * *\end{array}$ & $\begin{array}{l}-8.004 \\
* * *\end{array}$ & $-0.799^{* * *}$ & $-0.959 * * *$ & -0.178 & $-1.383^{* * *}$ & $-0.085^{* * *}$ & $-2.695^{* * *}$ \\
\hline South & $-0.469 * * *$ & $-6.984^{* * *}$ & $-0.703^{* * *}$ & $-0.658 * * *$ & $-0.179^{*}$ & $-1.269 * * *$ & $-0.099 * * *$ & $-2.276^{* *}$ \\
\hline West & $-0.350 * * *$ & $-3.602^{* * *}$ & $-0.327 * * *$ & $-0.507 * * *$ & -0.009 & $-0.599 * * *$ & $-0.060 * * *$ & $-2.222^{* *}$ \\
\hline Constant & -0.099 & $8.887 * * *$ & 1.494 & $1.048^{* * *}$ & 0.116 & 0.132 & 0.022 & 1.368 \\
\hline $\mathrm{R}$-squared & 0.225 & 0.264 & 0.325 & 0.415 & 0.485 & 0.348 & 0.227 & 0.052 \\
\hline
\end{tabular}

Source: Authors' calculations from U.S. Bureau of Labor Statistics, National Compensation Survey (NCS) restricted-use microdata extract, 2010-11.

Notes: Sample includes savings and thrift plans with flat employer match structures. Significance is denoted by $* \mathrm{p}<.10, * * \mathrm{p}<.05$, and $* * * \mathrm{p}<.01$. Breusch-Pagan test of independence: chi2 $=5077.233, \operatorname{Pr}=0.0000$. Other controls include dummies for imputed costs. Joint test of significance of autoenrollment: chi2 $=19.84, \operatorname{Pr}=0.0109$. 
Fig. 1. Prevalence of Automatic Enrollment by Industry

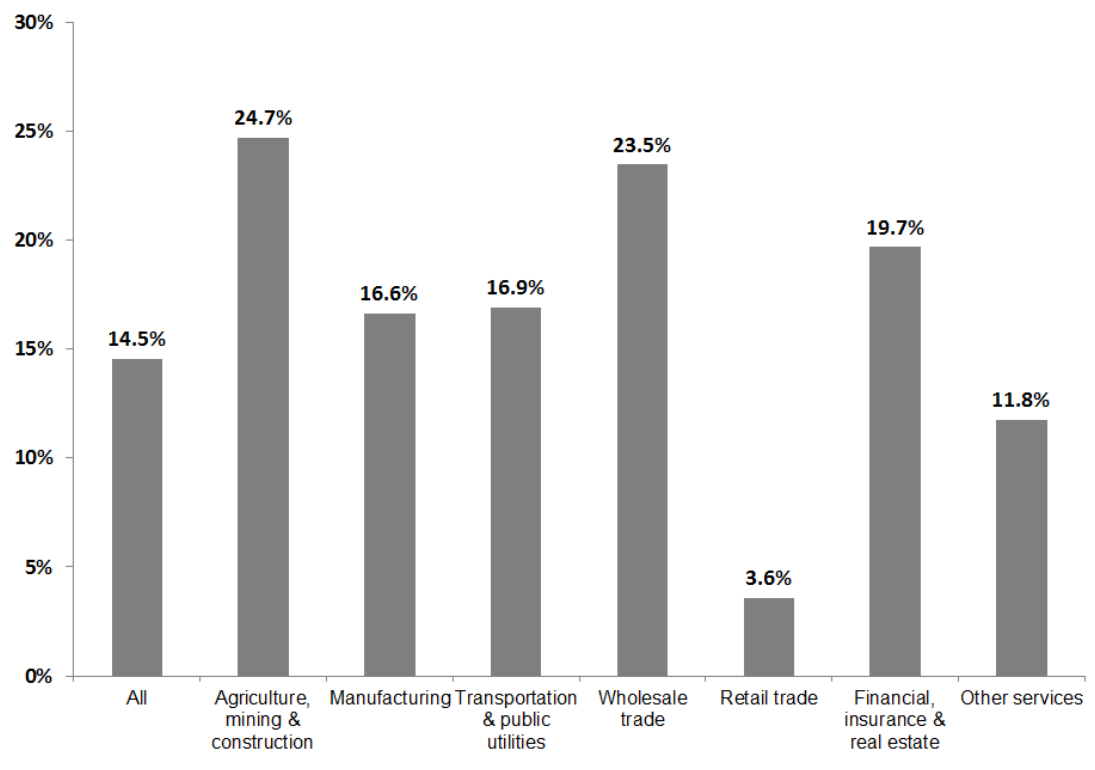

Source: Authors' calculations from U.S. Bureau of Labor Statistics, National Compensation Survey (NCS) restricted-use microdata extract, 2010-11.

Notes: Sample includes savings and thrift plans with flat employer match structures. Job-level weights were used to reflect the percentage of workers in the population. 
Fig. 2. Prevalence of Automatic Enrollment by Establishment Size

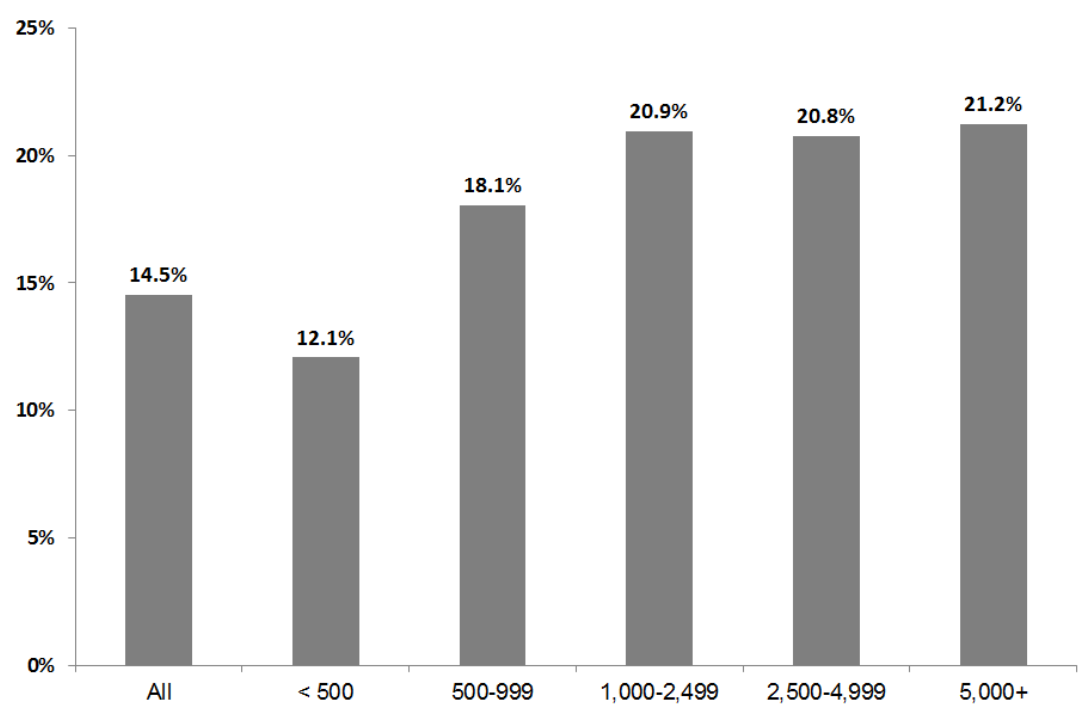

Source: Authors' calculations from U.S. Bureau of Labor Statistics, National Compensation Survey (NCS) restricted-use microdata extract, 2010-11.

Notes: Sample includes savings and thrift plans with flat employer match structures. Job-level weights were used to reflect the percentage of workers in the population. 
Fig. 3. Average Maximum Match of Workers by Industry and Autoenrollment

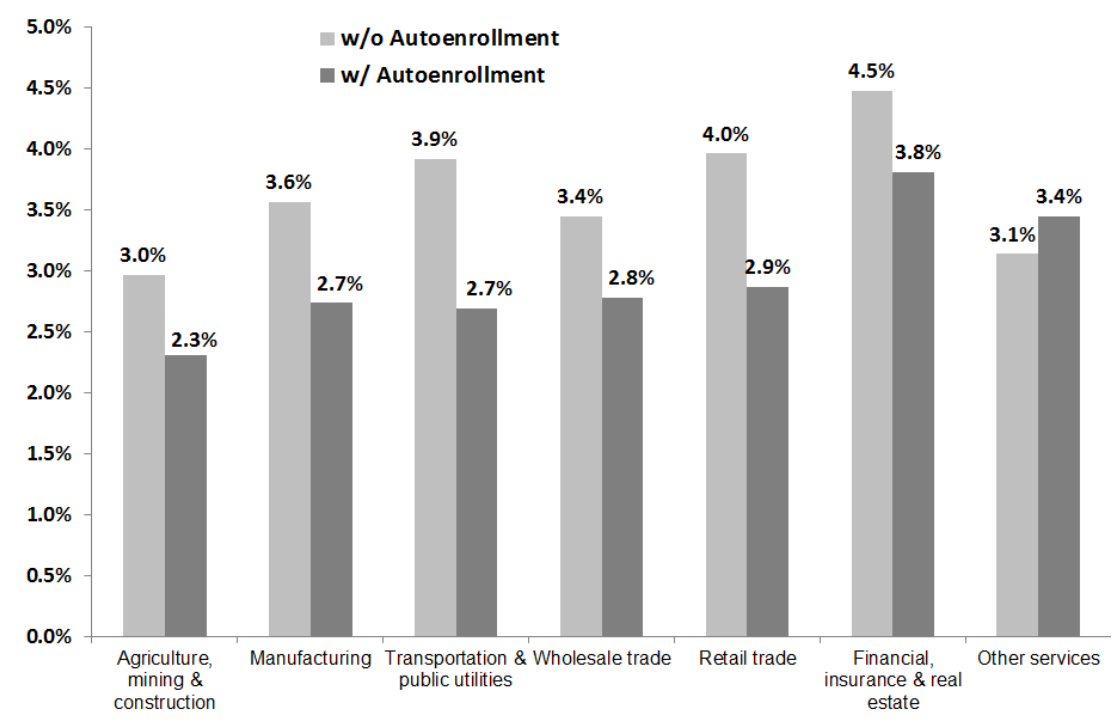

Source: Authors' calculations from U.S. Bureau of Labor Statistics, National Compensation Survey (NCS) restricted-use microdata extract, 2010-11.

Notes: Sample includes savings and thrift plans with flat employer match structures. Job-level weights were used to reflect the percentage of workers in the population. 
Fig. 4. Average Maximum Match of Workers by Establishment Size and Autoenrollment

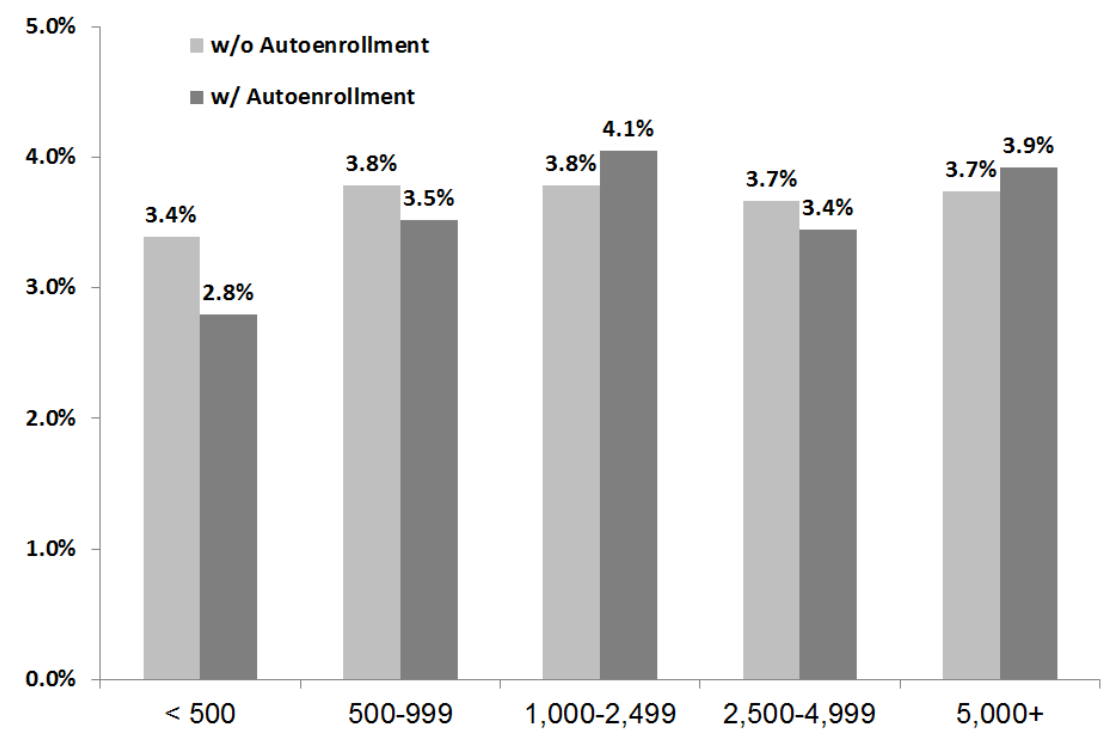

Source: Authors' calculations from U.S. Bureau of Labor Statistics, National Compensation Survey (NCS) restricted-use microdata extract, 2010-11.

Notes: Sample includes savings and thrift plans with flat employer match structures. Job-level weights were used to reflect the percentage of workers in the population. 
Fig. 5. Distribution of Maximum and Default Match by Autoenrollment

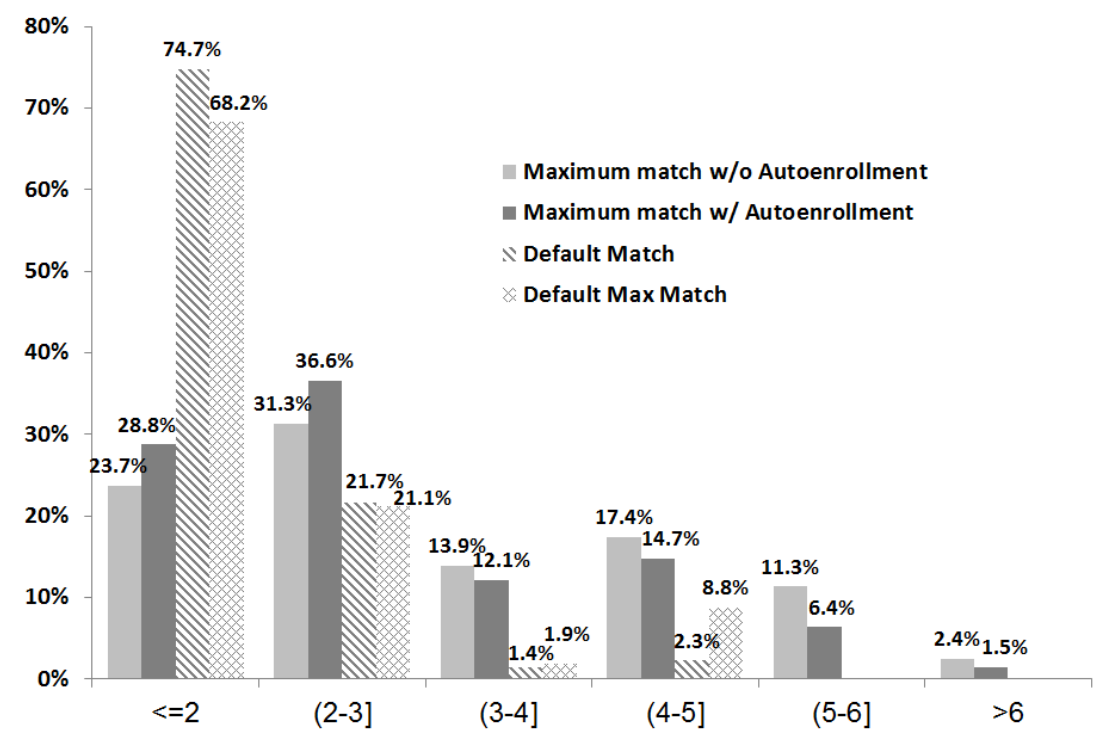

Source: Authors' calculations from U.S. Bureau of Labor Statistics, National Compensation Survey (NCS) restricted-use microdata extract, 2010-11.

Notes: Sample includes savings and thrift plans with flat employer match structures. Job-level weights were used to reflect the percentage of workers in the population. 


\section{Notes}

${ }^{1}$ The Survey of Income and Program Participation shows that 59 percent of eligible workers in the bottom income tercile participate in a DC plan, compared with 85 percent of those in the top tercile (Karamcheva and Sanzenbacher (2013)).

${ }^{2}$ Adams (2011) reports that only 3 out of 10 plan sponsors say "all or nearly all" of their participants defer enough income to take full advantage of the maximum employer match.

${ }^{3}$ Even among full-time workers - whose participation rates are typically higher - participation rates were 91 percent in DB pensions but only 74 percent in DC plans (U.S. Bureau of Labor Statistics (2012b)).

${ }^{4}$ See Brady (2007) for a brief exposition of the cross-subsidizing incentives from nondiscrimination testing.

${ }^{5}$ Of the sponsors who implemented automatic enrollment, 43 percent found a positive impact of automatic enrollment on their nondiscrimination test results and only 1 percent found the effect to be negative.

${ }^{6}$ A Hewitt survey of large U.S. firms found that 59 percent of employers in 2010 had adopted automatic enrollment for new employees, up from 24 percent in 2006 before the PPA. Another 27 percent of firms without automatic enrollment reported that they were likely to adopt it within a year (Atchison (2010)). In their annual survey of member companies, the Plan Sponsor Council of America (PSCA) reported that 46 percent of plans had an automatic enrollment feature in 2011, up from 24 percent in 2006 and 4 percent in 1999 (PSCA (2012); Soto and Butrica (2009)).

${ }^{7}$ Specifically, the PPA removed disincentives to adopting automatic enrollment by: 1) offering more attractive safe harbor rules; 2) preempting state payroll-withholding laws; and 3) protecting employers from fiduciary responsibility for their 401(k) plan's investment performance (Patterson, Veal, and Wray (2006); Purcell (2007))). According to O'Hare and Amendola (2007), prior to the PPA, many employers were hesitant to automatically enroll employees because of state payroll-withholding laws that might subject them to lawsuits by plan participants. Indeed Engelhardt (2011) finds that since the PPA, 401(k) participation increased more in states that required employees' written permission before employers could deduct contributions from their wages.

${ }^{8}$ A recent Plan Sponsor Council of America survey reported that the most common default deferral is 3 percent of pay (PSCA (2012)). Purcell (2007) notes that many plan sponsors have been reluctant to set the default contribution rate higher than 3 percent of pay because that was the rate used in examples of permissible automatic enrollment practices published by the IRS.

${ }^{9}$ The NCS excludes several types of workers from its survey scope including workers who set their own pay such as owners/officers/board members of incorporated firms, workers in positions with token pay, and student workers in set aside positions. The NCS removes these workers from its total employment count based on the frequency of such workers in sampled establishments as identified during sample initiation.

${ }^{10}$ Similarly, wages are averaged across workers in a particular job, which potentially obscures intra-job wage variation.

${ }^{11}$ See section 10.5 in Holmer, Janney, and Cohen (2012) for more information.

${ }^{12}$ Automatic enrollment is much less prevalent in our data than in industry studies. For example, PSCA (2012) reports that 46 percent of plans had automatic enrollment in 2011. We believe the difference in numbers may be due to differences in the samples. Our sample includes only savings and thrift plans with flat match structures. Among workers in all savings and thrift plans in our data, including those with tiered match structures, 19 percent have an autoenrollment provision. As an alternative measure, 25 percent of establishments with savings and thrift plans have at least one plan with automatic enrollment. Furthermore, our sample is nationally representative, and our reported statistics represent the percentage of workers in these plans. In contrast, most industry studies are based on large plans and are not nationally representative.

${ }^{13}$ Overall, only 12 percent of the workers in our sample have wages in the bottom tercile of the wage distribution, while 54 percent have wages in the top tercile. Because the terciles are based on the overall distribution of wages - including both establishments with and without DC plans, this result reflects the fact that higher wage workers are more likely to have access to DC plans.

${ }^{14}$ Unfortunately, we do not observe employee contribution rates in the data, so we cannot ascertain to what degree employees stay at the default contribution rate and to what extent that contributes to keeping employers' matching costs low. At best, when analyzing total DC costs, our results show these two factors working in combination and we are not able to separately identify their effects.

${ }^{15}$ See also Dworak-Fisher 2007 )

16 Dworak-Fisher (2007) discusses the correlation between the maximum match rate and DC costs in savings and thrift plans. The strongest relationship he finds is in a regression of employers' DC costs per labor hour on the maximum dollar match multiplied by the job's participation rate in the plan. The resulting measure accounts for 43 percent of the variation in employer costs for defined contribution plans, and its estimated effect on costs is close to 1 (a slope coefficient of 0.82). 
${ }^{17}$ Note that most of the results in the literature are based on case studies of a handful of firms that have switched to automatic enrollment. One advantage of our data is that it is nationally representative; hence, we can draw conclusions that relate to the population of workers. However, some of the drawbacks of our data are that we can only study savings and thrift plans and only a subset of them that have positive match rates and a flat match structures. Also, we can only observe firms at one point in time instead of before and after autoenrollment, and we do not have information about how much time has elapsed since firms instituted the autoenrollment feature in their plans. Hence, we cannot draw a clear picture of causality in this or the following regressions.

${ }^{18}$ Choi et al. (2004) conclude from the literature that the rate at which employers match employee contributions has at most a small effect on participation and that the impact of automatic enrollment is much greater. Using earlier data from the NCS, Dworak-Fisher (2011) found positive effects of matching on participation - insignificant in an OLS specification, but strong and significant in an instrumental variables regression.

${ }^{19}$ In addition, we conducted the multivariate analysis constricting the sample to include only observations without imputed plan or cost data. Since the estimated relationships between the variables of interest did not change noticeably and because of sample size considerations, our preferred model specifications include the flag controls for imputed data.

${ }^{20}$ We use the estimator proposed by Zellner 1962$)$. We write the SUR model as: $y_{i}=X_{i} \beta_{i}+\epsilon_{i}, i=1, \ldots, M$ where $y_{i}$ is the ith equation's dependent variable, on which we have $\mathrm{T}$ observations. The error process $\epsilon=\left[\epsilon_{1}^{\prime}, \epsilon_{2}^{\prime}, \ldots, \epsilon_{M}\right]$ is assumed to have an expectation of zero and a covariance matrix of $\Omega$. We assume that $\left[\epsilon_{i t} \epsilon_{j s}\right]=\sigma_{i j}, t=s$ otherwise zero, to allow the error terms in different equations to be contemporaneously correlated, but assuming that they are not correlated at other points. The efficient estimator for this problem is generalized least squares, which we implement in Stata via the SUREG command. If all the equations in our SUR specification have the same number of observations and a common set of independent variables, then the coefficients would be identical to OLS; however, estimating a SUR model allows for tests of cross-equation constraints.

${ }^{21}$ The Breusch-Pagan test of independence, however, strongly rejects the hypothesis that the error terms are uncorrelated $(p<.01)$, indicating that the SUR model is the appropriate specification.

${ }^{22}$ We also estimated models for the share of total costs that various benefits comprise and found no evidence that firms with autoenrollment spend a larger or smaller share of their total costs on DC plans than those without autoenrollment. The results are available from the authors upon request.

${ }^{23}$ If the selection for example is driven by unobservable differences in workers' productivity, such as when potentially more productive workers self-select into firms that pay higher compensation and are also more likely to institute automatic enrollment. 